\title{
Functional mapping of the human papillomavirus type 11 transcriptional enhancer and its interaction with the trans-acting E2 proteins
}

\author{
Hirohiko Hirochika, Rei Hirochika, Thomas R. Broker, and Louise T. Chow ${ }^{1}$ \\ Biochemistry Department, University of Rochester, School of Medicine and Dentistry, Rochester, New York 14642 USA
}

\begin{abstract}
The transcriptional enhancer sequences of the papillomaviruses are regulated by trans-acting factors encoded by the viral E2 open reading frame. We have performed detailed functional and physical analyses of the enhancer of the human papillomavirus type 11 (HPV-11). Using the chloramphenicol acetyltransferase (CAT) assay in transiently transfected monkey CV-1 cells, the enhancer region has been localized to a 270-bp tract immediately preceding the $\mathrm{E} 6$ open reading frame, and it consists of two functional components. The first is a constitutive enhancer containing sequences homologous to the GT-, Sph-, and P-motifs found in the SV40 and polyomavirus enhancers; others resemble the recognition sequence for CTF (NF-1), a factor which stimulates transcription of certain eukaryotic genes and replication of adenovirus DNA. The second component is an inducible enhancer with a consensus sequence $\mathrm{ACCN}_{6} \mathrm{GGT}$ responsive to the $\mathrm{E} 2$ protein encoded by papillomaviruses. Tandem copies of portions of the constitutive enhancer function as an E2-independent enhancer, whereas multiple copies of HPV-11 DNA restriction fragments or synthetic oligonucleotides containing the E2-responsive sequence (E2-RS) act as an enhancer in the presence of the E2 protein encoded by HPV-1, HPV-11, or bovine papillomavirus type 1 (BPV-1). The inducible activity is lost when mutations are introduced into the E2-RS or when a mutant palindromic sequence is substituted. We have also expressed the E2 proteins of HPV-1, HPV-11, and BPV-1 in Escherichia coli and studied their physical interactions with the E2-responsive sequence in vitro. Filter-binding analyses with crude Escherichia coli lysates show that the E2 proteins bind to the E2-RS, but not to mutated motifs, with an affinity proportional to the copy number. These E2 proteins have been purified to near-homogeneity by sequence-specific DNA affinity chromatography using the synthetic E2-RS as a ligand. The purified proteins protect a DNA segment containing the E2-RS and several flanking nucleotides in pancreatic DNase I footprinting analyses. Based on these results, we conclude that E2 proteins activate the enhancer by binding directly to the E2-RS and interacting with other transcriptional factors and that the sequence $\mathrm{ACCN}_{6} \mathrm{GGT}$ is both necessary and sufficient for the E2 protein binding in vitro and for activation of RNA transcription in vivo.
\end{abstract}

[Key Words: Human papillomavirus; enhancer; transcription factor; protein expression; DNA-protein interactions]

Received August 25, 1987; revised version accepted November 11, 1987.

The large family of animal and human papillomaviruses each contain a circular, double-stranded DNA genome of approximately 7900 nucleotides pairs. They have strict species- and tissue-specificity. Infliction with human papillomaviruses is generally manifested as hyperproliferation of the cutaneous or mucosal epithelia. HPV types 6 and 11 (HPV-6 and -11) are often found in benign anogenital lesions called condylomata acuminata. Experimental infection of human foreskin chips with HPV-11 followed by implantation under the renal capsules of athymic $(\mathrm{nu} / \mathrm{nu})$ mice has clearly demonstrated that it indeed is the etiological agent of venereal warts

${ }^{1}$ Corresponding author.
(Kreider et al. 1985). HPV-16, -18, -31, -33, and -35, as well as several newly identified types, are found in lesions with a potential for oncogenic progression to highgrade dysplasia, carcinoma-in-situ, and cervical carcinoma (for review, see zur Hausen and Schneider 1987). Moreover, most cell lines established from cervical carcinomas contain transcriptionally active, integrated HPV-16 and -18 DNA sequences (Pater and Pater 1985; Schwarz et al. 1985; Yee et al. 1985; Schneider-Gadicke and Schwarz 1986; Takebe et al. 1987; Shirasawa et al. 1987). However, our knowledge about human papillomaviral gene expression, as well as their mechanism of tumorigenesis, is limited, primarily due to the inability to propagate these viruses in any tissue culture system. Electron microscopic heteroduplex analyses/Croissant 
et al. 1982; Beaudenon et al. 1986; Broker and Chow 1986; Chow et al. 1987c; Krubke et al. 1987) and nucleotide sequence comparisons reveal that all papillomaviruses have similar genetic organization despite substantial nucleotide sequence divergence (Baker 1987). Consistent with this genetic homology, mRNAs of HPV $-16,-1,-6$, and -11 recovered from cervical carcinomas, plantar warts, and condylomata acuminata, respectively (Smotkin and Wettstein 1986; Chow et al. 1987a,b; Nasseri et al. 1987), and HPV-16 mRNAs from transformed mouse cells (Yasumoto et al. 1987) are rather similar to those of bovine papillomavirus type 1 (BPV-1) present in fibropapillomas and in transformed mouse cells (Stenlund et al. 1985; Yang et al. 1985; Baker and Howley 1987) and to those of cottontail rabbit papillomavirus in tumors (Nasseri and Wettstein 1984; Danos et al. 1985; Phelps et al. 1985). Production of viral messages relies upon alternative usage of promoters, mRNA splice sites, and polyadenylation sites for accessing the various open reading frames (ORFs) deduced from the DNA sequences. The functions of the ORFs were determined using BPV-1, which transforms mouse cell lines readily and replicates as a multicopy, extrachromosomal plasmid, as in vivo (for reviews, see Broker and Botchan 1986; Broker 1987).

To understand the expression and regulation of the viral genes, a number of laboratories have used the chloramphenicol acetyltransferase (CAT) assay to identify the cis-and trans-acting elements that regulate transcription. A trans-acting factor encoded by the BPV-1 E2 ORF is necessary for the activation of the enhancers and promoters located in the long control region (LCR) (Spalholz et al. 1985, 1987; Yang et al. 1985; Haugen et al. 1987). The LCR is situated upstream from the early region and is devoid of any long and obvious ORF in almost all papillomaviral DNAs sequenced. The LCR is also called the upstream regulatory region (URR), or the noncoding region (NCR), by different investigators. An E2-dependent enhancer in HPV-16 has also been found (Phelps and Howley 1987). We have previously reported the presence of analogous enhancers located in the URR of many different human papillomaviruses and cottontail rabbit papillomavirus, in addition to those of BPV-1 and HPV-16 (Hirochika et al. 1987; Chow et al. $1987 \mathrm{c}$ ). These enhancers are cross-activated by E2 proteins from HPV-1, HPV-11, or BPV-1. We and others have suggested that the sequence ACCGN $_{4}$ CGGT found in one or multiple copies in the URR of these viruses might be the target for E2 protein activation. However, this has not yet been proven in a stringent manner.

Many virus-encoded transcriptional factors have been described. The DNA binding sites of only a few of these factors are known (Kristie and Roizman 1986; and reviews by Wong-Staal and Gallo 1985 and by McKnight and Tiian 1986). On the other hand, the well-characterized E1A regulatory proteins of adenoviruses are thought not to bind directly to the regulatory sequences of the viral genome but instead to function indirectly through a host protein (Yoshinaga et al. 1986). The papilloma- viruses provide an excellent opportunity for dissecting the cis elements in the regulation of mRNA transcription and for studying the mechanism of activation by the viral trans-acting factors. To achieve these goals, we have made a large number of $5^{\prime}$ and $3^{\prime}$ deletions in the HPV-11 URR to localize the enhancer sequences and to identify its subelements. We have also chemically synthesized the sequence motif $\mathrm{ACCGN}_{4}$ CGGT and mutant versions of it. The abilities of these sequences to function as enhancers in the presence or absence of the E2 proteins were studied by CAT assays in CV-1 cells. We have learned that the enhancer consists of two components: one is constitutive, the other is E2-responsive. Furthermore, we have studied the interactions between E2 proteins of HPV-11, HPV-1, and BPV-1 expressed in Escherichia coli and DNA restriction fragments containing synthetic or natural HPV-11 E2-responsive sequences. Our results clearly demonstrate that these three E2 proteins bind to the E2-responsive sequence ACCGN $_{4}$ CGGT identified by the CAT assays and leave footprints extending a few nucleotides beyond the motif. We have also established that the $\mathrm{ACCN}_{6} \mathrm{GGT}$ sequence is both necessary and sufficient for the binding of homologous or heterologous E2 proteins in vitro and for enhancer activation in vivo.

\section{Results \\ Localization of the enhancer sequence of HPV-11 by deletion analysis}

We have previously used the CAT assay to identify enhancer sequences in human and animal papillomavirus genomes. Substantial HPV-11 enhancer activity is located in the DNA segment in plasmid pUR21 (nucleotides 7072-7904). This activity is dependent on a transacting function encoded by the E2 ORF of HPV-11, HPV-1, or BPV-1 (Hirochika et al. 1987). We have shown that the CAT activity reflects the steady-state level of the CAT mRNA. To dissect the cis-acting elements in the enhancer, we made two sets of $5^{\prime}$ or $3^{\prime}$ deletion mutations of the HPV-11 URR in pUR21 by BAL31 nuclease resection. Deleted fragments were placed upstream from the enhancerless-SV40 early promoter and the CAT gene contained in plasmid pCAT-A. E2-dependent and E2-independent CAT activities were assayed after cotransfection of CV-1 cells with a plasmid expressing E2 protein from a Rous sarcoma virus LTR promoter or with the control plasmid pUC18, respectively. Of the HPV-1, HPV-11 and BPV-1 E2 expression plasmids, the BPV-1 plasmid, pRSE2-BP, led to the highest induction of the HPV-11 enhancer (Hirochika et al. 1987) and was used in this study to delineate the E2responsive sequences of $\mathrm{HPV}-11$.

Table 1 summarizes the results of these analyses. 5' deletions extending to nucleotide 7674 reduced the E2independent activity slightly. Deletion to nucleotide 7728, however, increased both E2-dependent and E2-independent activities. Further deletions led to gradual de- 
Table 1. Fine mapping of HPV-11 enhancer sequences by Bal31 deletion analysis

\begin{tabular}{|c|c|c|c|c|c|}
\hline \multirow[b]{2}{*}{ Plasmid } & \multirow{2}{*}{$\begin{array}{l}\text { DNA fragment } \\
\text { cloned } \\
\text { (nucleotide) }\end{array}$} & \multicolumn{2}{|c|}{ CAT activity $(\%)$} & \multirow{2}{*}{$\begin{array}{l}\text { Fold stimulation } \\
\text { by E2 }\end{array}$} & \multirow[b]{2}{*}{ Copies of E2-RS } \\
\hline & & $-\mathrm{E} 2$ & $+E 2$ & & \\
\hline pUR21 & $7072-7904$ & 1.8 & 17.7 & 9.8 & $\# 1, \# 2$ \\
\hline $3-1$ & $7450-7904$ & 0.9 & 15.0 & 16.7 & $\# 1, \# 2$ \\
\hline $24-\mathrm{N}$ & $7674-7904$ & 1.1 & 13.0 & 11.8 & \#2 \\
\hline $10-N$ & $7713-7904$ & 3.6 & 24.0 & 6.7 & $\# 2$ \\
\hline $27-N$ & $7722-7904$ & 2.9 & 27.0 & 9.3 & $\# 2$ \\
\hline $14-\mathrm{O}$ & $7728-7904$ & 4.3 & 28.0 & 6.5 & $\# 2$ \\
\hline $30-0$ & $7736-7904$ & 3.5 & 15.2 & 4.3 & $\# 2$ \\
\hline $8-\mathrm{N}$ & $7761-7904$ & 3.2 & 18.6 & 5.8 & $\# 2$ \\
\hline $16-3$ & $7792-7904$ & 1.1 & 6.7 & 6.1 & $\# 2$ \\
\hline $5-3$ & $7808-7904$ & 0.5 & 3.1 & 6.2 & $\# 2$ \\
\hline $3-9$ & $7820-7904$ & 0.8 & 4.2 & 5.3 & $\# 2$ \\
\hline $\mathrm{H}$ & $7072-7893$ & 2.9 & 10.0 & 3.4 & $\# 1$ \\
\hline 11 & $7072-7871$ & 2.9 & 9.5 & 3.2 & $\# 1$ \\
\hline 15 & $7072-7847$ & 2.4 & 6.3 & 2.6 & $\# 1$ \\
\hline 18 & $7072-7832$ & 1.0 & 2.5 & 2.5 & $\# 1$ \\
\hline 24 & $7072-7801$ & 0.8 & 2.3 & 2.9 & $\# 1$ \\
\hline $4-2-23$ & $7072-7787$ & 0.6 & 1.3 & 2.2 & $\# 1$ \\
\hline $4-2-8$ & $7072-7750$ & 0.8 & 1.4 & 1.8 & $\# 1$ \\
\hline 4-1 & $7072-7670$ & 0.6 & 1.6 & 2.7 & $\# 1$ \\
\hline $4-11$ & $7072-7490$ & 0.6 & 2.2 & 3.7 & - \\
\hline $4-2$ & $7072-7275$ & 0.4 & 1.6 & 4.0 & - \\
\hline pUR26 & $7072-20$ & 0.6 & 10.1 & 16.8 & $\# 1, \# 2$ \\
\hline pUR27 & $7072-64$ & 0.6 & 29.3 & 48.8 & $\# 1, \# 2, \# 3, \# 4$ \\
\hline pCAT-A & - & 1.2 & 3.4 & 2.8 & - \\
\hline
\end{tabular}

Each of the CAT plasmids was transfected into CV-1 cells with pRSE2-BP (+E2) or pUC18 (-E2). The CAT activities are the percentages of conversion of chloramphenicol to monoacetylated forms and are averages for four independent experiments.

creases in both activities. The sequences deleted resemble the Sph-, GT-, or P-motifs found in the SV40 and polyoma virus enhancers (Zenke et al. 1986) and the recognition sequence for CTF (NF-1), which stimulates RNA polymerase II transcription from certain eukaryotic genes and DNA replication of adenoviruses (Jones et al. 1987) (Fig. 1). 3' deletions from nucleotide 7904 led to slight modulations in E2-independent activity but caused an immediate reduction of stimulation by E2 protein to background level (compare pCAT-A and clone $\mathrm{H}$, Table 1, last column). In contrast, the positive response to E2 protein was not abolished by the $5^{\prime}$ deletions. These results indicated that the E2-responsive sequence (E2-RS) was located near nucleotide 7904 and was destroyed in clone $\mathrm{H}$ by the $3^{\prime}$ deletion. This region carries the sequence ACCGN ${ }_{4}$ CGGT (\#2 copy in Figs. 1 and $9 \mid$ which is conserved in the URR of all papillomaviruses sequenced (Giri et al. 1985; Dartmann et al. 1986; Cole and Danos 1987; Krubke et al. 1987). In the URR of HPV-11, there are four copies of the ACCGN $_{4}$ CGGT motif (see Fig. 9). Our 5' deletion analysis showed that copy \#1 (nucleotides 7592-7603) was not essential for the transcriptional response of these clones to E2 protein (Table 1). To determine whether copies \#3 and \#4 of this motif formed part of the E2-RS, we constructed and tested two additional plasmids, pUR26 and pUR27. pUR26 contains nucleotides 7072-20 and has the copies \#1 and \#2 motif, as does
pUR21, whereas pUR27 spans nucleotides 7072-64 and also includes copies \#3 and \#4 just upstream from the putative promoter (TATA element) for the E6 ORF. Only pUR27, but not pUR26, had a dramatically higher response to E2 protein than pUR21 (Table 1 and Fig. 1). Together these results indicate that the HPV-11 enhancer is located between nucleotides 7728 and 64 and is composed of two functional components: (1) a constitutive enhancer necessary for both E2-dependent and E2-independent activities; and (2) multiple copies of an E2-responsive sequence ACCGN ${ }_{4}$ CGGT. The boundary between these two components is defined by the \#2 E2-RS near nucleotide 7889 (see Fig. 9).

\section{Fine structure mapping of the enhancer sequence}

To dissect the enhancer further, we cloned different portions of the enhancer region into PCAT-A and assayed their abilities to function as enhancers in the presence or absence of the BPV-1 E2 protein in CV-1 cells. The fragments tested and the results obtained are shown in Figure 2. Fragment $\mathrm{C}$ contains one $\mathrm{ACCGN}_{4} \mathrm{CGGT}$ motif (\#2 copy of Figs. 1 and 9). pCAT-N1 and -N2 with one and two copies of fragment $\mathrm{C}$, respectively, had little or no activity. When four or more copies were cloned in tandem in either orientation relative to the CAT gene, E2-dependent activity was clearly evident (pCAT-N4 and pCAT-N6R). In contrast, four copies of 


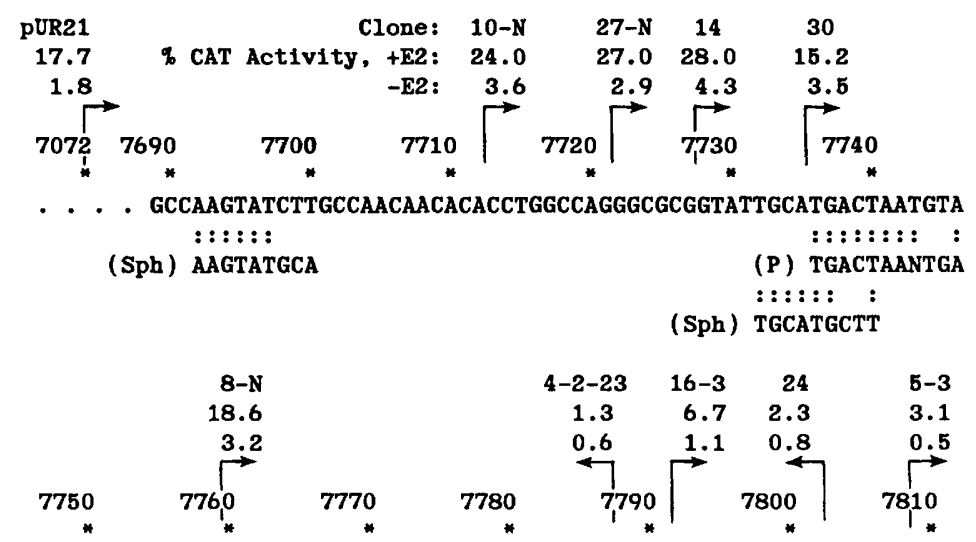

CAATAAACCTGTCGGTTTGTACAATGTTGTGGATTGCAGCCAAAGGTTAAAAGCATTTTTGGCTTC $::::::::::$

(GT) GGTGTGGATTGT

$:::::::::::::$ :

(CTF) TGGCTNNAGCCA

(Sph) AAGCATGCA

$::::::::$

(CTF) TGGCTNN

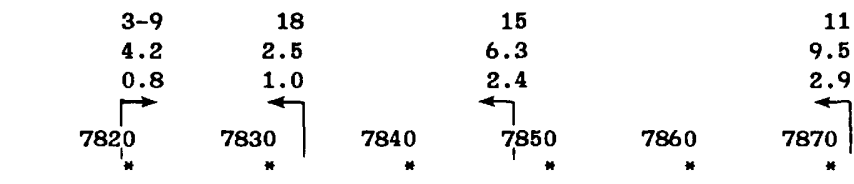

TAGCTGAACATTTTTGTACCCTTAGTATATTATGCACAATACCCACAAAATGAGTAACCTAAGGTC : :::::::

(Sph) AAGTATGCA

(P) :: ::::::

$:::: \quad:$

NAGCCAA
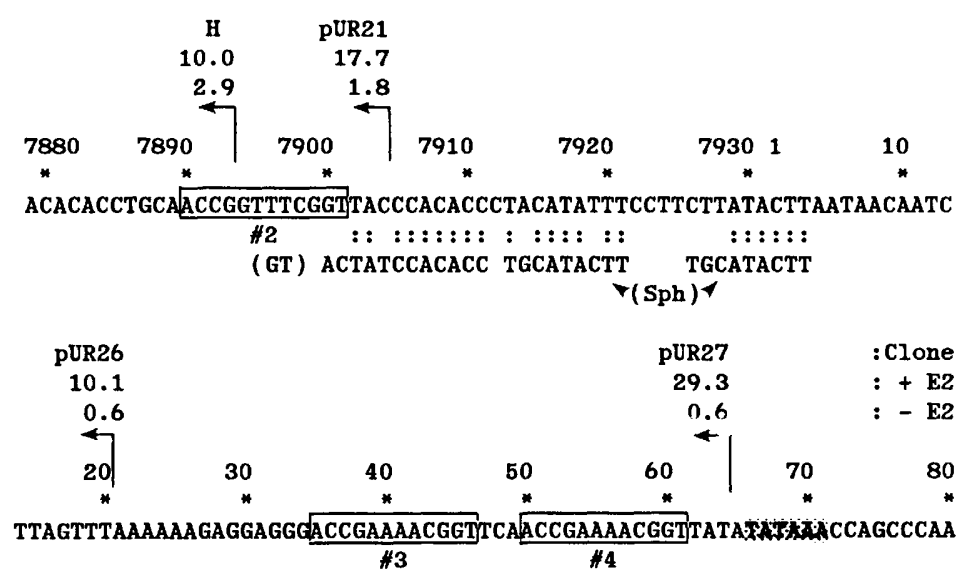

Figure 1. Sequence of the HPV-11 enhancer showing homologies to the SV40 enhancer motifs displayed underneath. CTF Recognition Sequence and Bent arrows denote the direction and the ends of the BAL31 deletions from upstream (nucleotide 7072) or downstream (nucleotide 7904) sites. The names of the deletion mutations and their CAT activities in the presence or absence of the BPV-1 E2 protein are shown above the arrows. Copies \#2, $\# 3$, and \#4 of the E2-RS ACCGN ${ }_{4}$ CGGT are boxed and so indicated. Copy \#1 is located at nucleotides $7592-7603$, the deletion of which had little effect on the E2-responsiveness (see Table 1). The TATA element of the putative E6 promoter is shaded. the control fragment $\mathrm{E}$ derived from $\mathrm{pUC19}$ (pCAT-46-4) did not have any enhancer activity. Very significantly, fragment $D$ in pUR27dl with two copies of the ACCGN $_{4}$ CGGT motif (\#3 and \#4) alone was an E2-dependent enhancer. These results support the interpretation that this motif is a major component of the E2-RS. The region contained in fragment $B$ is important for both E2-dependent and E2-independent activities, as shown by deletion analysis (Table 1). While the plasmid pCATGT1 containing one copy of fragment B did not have any activity, that with four copies (pCAT-GT4R) stimulated the CAT activities very substantially either in the presence or absence of $\mathrm{E} 2$ expression plasmid. pCAT-N $\left(5^{\prime}\right) 5$, which contains five copics of fragment A spanning the upstream boundary of the enhancer, showed little or no activity. These results are consistent with the conclu- sion that the region between nucleotides 7728 and 7889 carries a strong constitutive enhancer and suggest that the GT-motif and putative CTF recognition sequences may play a more important role in CV-1 cells than those resembling Sph- or P-motifs.

\section{Mutational analysis of the E2-responsive sequence}

To prove unequivocally that the $\mathrm{ACCGN}_{4} \mathrm{CGGT}$ sequence is the E2-RS, complementary oligonucleotides carrying this sequence or variations of it were chemically synthesized, cloned into pCAT-A, and assayed for enhancer activity. The results are shown in Figure 3. The plasmid pCAT-SN1 contains one copy of the wild type putative HPV-11 E2-RS between nucleotides 7890 and 7901 (Fig. 1). It had no higher E2-dependent activity 


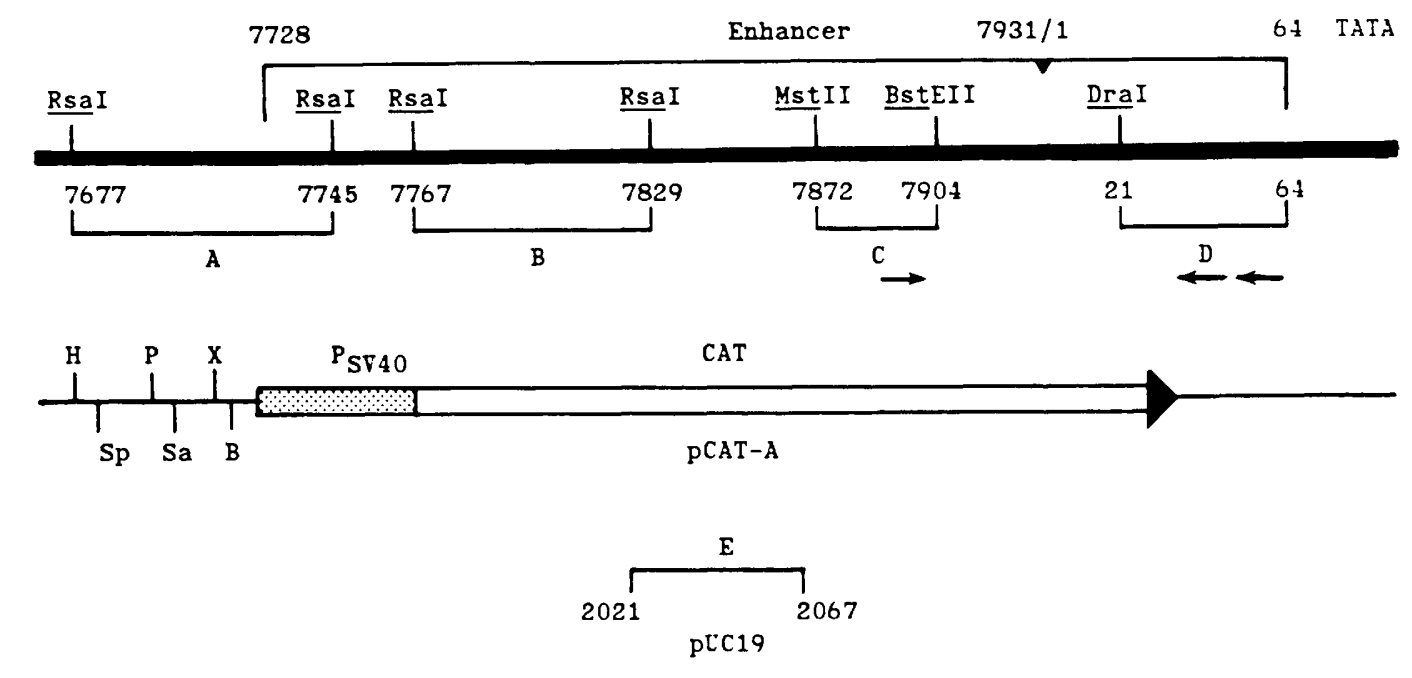

\begin{tabular}{|c|c|c|c|c|c|}
\hline & & agments & ned & Relative CAT & Activity \\
\hline Plasmid & Name & Copy \# & Orientation" & $-\mathrm{E} 2$ & $+\mathrm{E} 2$ \\
\hline pCAT-A & - & - & - & 1.0 & 1.0 \\
\hline pCAT-N1 & c & 1 & sense & 0.8 & 1.3 \\
\hline PCAT-N2 & c & 2 & sense & 0.6 & 1.5 \\
\hline PCAT-N4 & c & 4 & sense & 0.6 & 3.5 \\
\hline PCAT-N6R & c & 6 & antisense & 0.9 & 6.5 \\
\hline PCAT-GT1 & B & 1 & sense & 0.9 & 0.6 \\
\hline PCAT-GT4R & B & 4 & antisense & 26.4 & 15.2 \\
\hline pCAT-N(5,)1 & A & 1 & sense & 1.4 & 1.4 \\
\hline $\mathrm{PCAT}-\mathrm{N}\left(5^{\prime}\right) 5$ & A & 5 & sense & 1.8 & 1.9 \\
\hline p[R27d1 & D & 1 & sense & 0.9 & 4.7 \\
\hline pCAT-46-4 & $\mathbf{E}$ & 4 & N.D. & 0.9 & 0.6 \\
\hline
\end{tabular}

Figure 2. Dissection of the HPV-11 enhancer sequence. One or more copies of fragments (A-D) from the HPV-11 enhancer or fragment (E) of pUC19 were inserted into the multiple-cloning sites of pCAT-A. In pCAT-N1 through -N6R, fragment C was cloned at the $\mathrm{XbaI}$ site. In pCAT-GT1 and -GT4R, fragment B was cloned at the SalI site. In pCAT-N $\left(5^{\prime}\right) 1$ and $-\mathrm{N}\left(5^{\prime} \mathrm{L}\right) 5$, fragment A was inserted at the Sall site. pUR27d1, containing fragment D (nucleotide 21-64), was obtained by deleting the fragment spanning (nucleotides 7072-20 (BamHI-DraI) from pUR27. pCAT-46-4 was prepared by inserting fragment E from pUC19 into the BamHI site. The plasmids thus constructed were transfected into CV-1 cells with pRSE2-BP (+E2) or pUC18(-E2). The CAT activities relative to that of pCAT-A are averages from three independent experiments. $\left({ }^{*}\right)$ Relative to the CAT gene. Restriction endonuclease sites in the multicloning site: $(\mathrm{H})$ HindIII; $(\mathrm{Sp})$ SphI; $(\mathrm{P})$ Pst $\mathrm{I}_{;}(\mathrm{Sa})$ SalI; $(\mathrm{X})$ XbaI; (B) BamHI. The arrows under the restriction map indicate the locations and orientations of the ACCGN ${ }_{4}$ CGGT motifs with respect to the central four nucleotides (see Fig. 9). (N.D.) Not determined

than pCAT-A. However, the E2-dependent activity was evident when either two or five copies (pCAT-SN2, pCAT-SN5) were cloned in various orientations. The synthetic E2 motif was also functional when multiple copies were placed downstream of the CAT gene (pCAT-SN5D). The cloned sequences have no effect in the absence of $\mathrm{E} 2$ protein. The alteration of ACCGN ${ }_{4}$ CGGT to AGGGN ${ }_{4}$ CGGT completely abolished the E2-dependent enhancer activity. Also tested was a clone with five copies of the sequence AGGGN ${ }_{4} \mathrm{CCCT}$ which re-established the palindromic nature of the wild type motif. This second-site mutation did not restore any E2-dependent enhancer activity.
From these results we conclude that the ACCGN ${ }_{4}$ CGGT sequence is the E2-RS and that two or more tandem copies of this sequence function as an E2inducible enhancer, even in the absence of the constitutive enhancer element. This interpretation is consistent with the orientation- and location-independent nature of this inducible element.

\section{Specificity of different E2 proteins}

We have used the BPV-1 E2 expression plasmid to identify the E2-RS of HPV-11. The same conclusion was also reached by using HPV-11 and HPV-1 E2 proteins as tran- 
SN

SNMutant

SNPalindrome
5' -TCGACA ACCGGTTTCGGTT-3' 3'-GITGGCCAAAGCCAAAGCT-5,

5 - TCGACA AGGGGTTTCGGTT-3' 3'-GITCCCCAAAGCCAAAGCT-5'

5' -TCGACA AGGGGTTTCCCTT-3' 3'-GTTCCCCAAAGGGAAGCT-5,
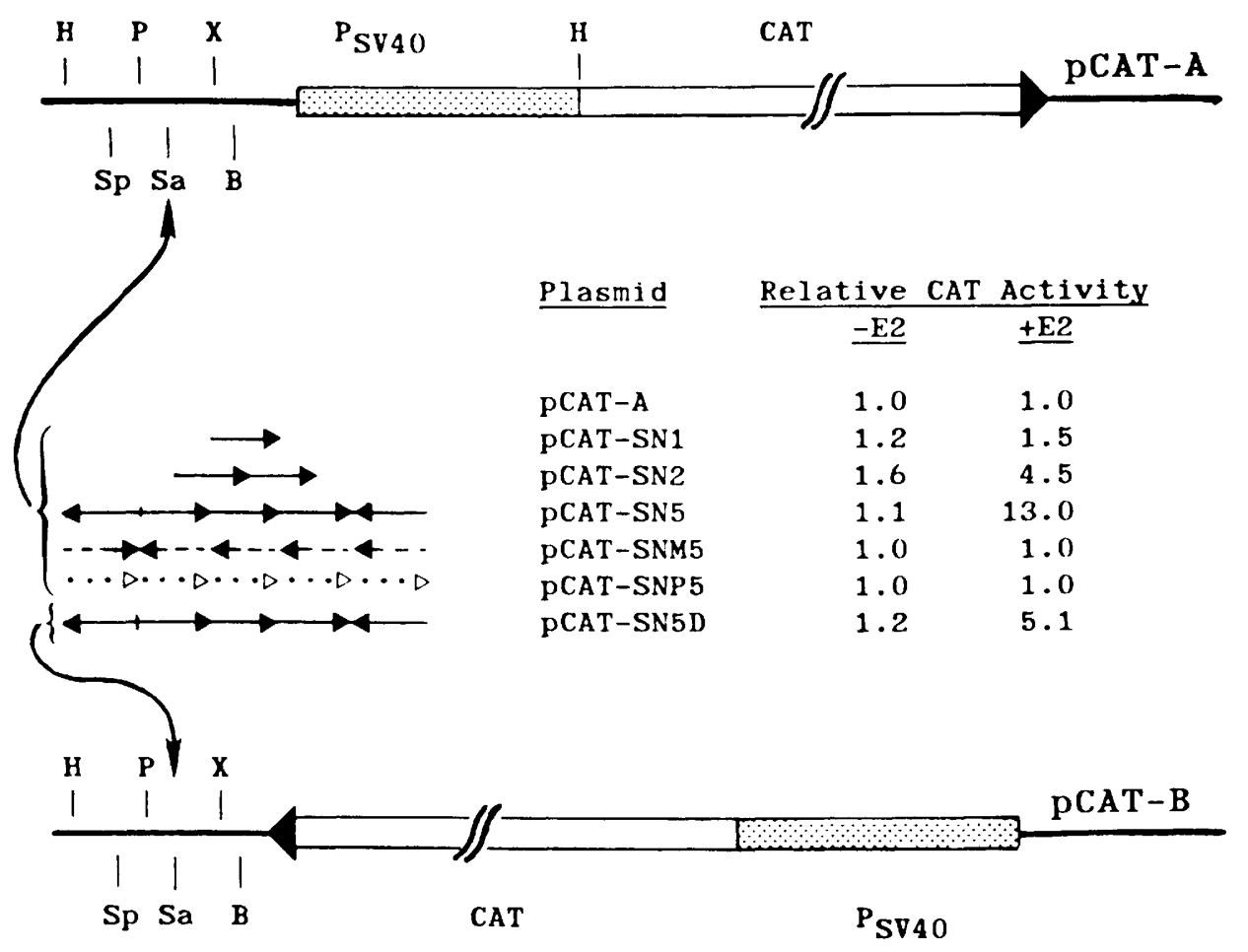

Figure 3. Mutational analyses of the E2-responsive sequence. Three sets of complementary 19 nucleotide sequences were synthesized chemically and cloned into the SalI site of pCAT-A or pCAT-B. The different types of arrows indicate the orientations of each of three 19 -mers in the clone. The ACCGN ${ }_{4}$ CGGT motif and its variants are boxed. The altered nucleotides are underlined. The resulting plasmids were transfected into CV-1 cells with pRSE2-BP (+E2) or pUC18 (-E2). The relative CAT activities are shown and are averages of three independent experiments. (SNM) SNMutant; (SNP) SNPalindrome.

sactivators, as shown in Figure 4. Any of the three E2 proteins expressed from the Rous sarcoma virus promoter (Hirochika et al. 1987) activated pUR21 and pCAT-SN5 which contain the HPV-11 URR or five copies of the synthetic E2-RS, respectively. There was no CAT activity when the E2 plasmids were omitted. The mutation in the E2-RS in plasmid pCAT-SNM5 abolished the response to all E2 proteins. These experiments prove unequivocally that $\mathrm{ACCGN}_{4} \mathrm{CGGT}$ is the target sequence for all three E2 proteins and multiple copies of this motif function as an enhancer in the absence of the constitutive enhancer. The BPV-1 E2 slightly stimulated the CAT gene expression of pCAT-A which lacks an enhancer (Fig. 4), as also noted by Haugen et al. (1987). This observation suggests a somewhat different property of BPV-1 E2 protein compared with those of HPV-1 and HPV-11, which did not stimulate pCAT-A.
In vitro analysis of interactions between E2 proteins and E2-responsive sequences

To investigate the nature of the interaction between the E2 proteins and the E2-RS, we examined the DNA binding activity in vitro of the $\mathrm{E} 2$ proteins expressed in E. coli. The structures of the expression plasmids are shown in Figure 5A. HPV-11 and BPV-1 E2 proteins were produced from vectors $\mathrm{pRC} 23$ and $\mathrm{pEV}$-vrf1, respectively, under the control of the inducible $\lambda$ promoter $P_{L}$ (Crowl et al. 1985). HPV-1 E2 was expressed from the vector pKK223-3 (Pharmacia) under the control of the hybrid tac promoter. HPV-11 and HPV-1 E2 proteins were each initiated from the first AUG of the E2 ORF, the putative initiation codon, whereas the BPV-1 E2 protein was expressed as a truncated fusion protein in which four amino acids from the vector replaced the amino-terminal one-fourth of the E2 ORF. After induc- 
Figure 4. Specificity of E2 proteins of HPV-11, HPV-1, and BPV-1. Each of the CAT plasmids was transfected into $\mathrm{CV}-1$ cells with each of the E2 expression plasmids or with pUC18. The E2 expression plasmids used were pRSE2-BP for BPV-1 E2, pRSE2 (6-1) for HPV-1 E2, and pRSE211 for HPV-11 E2 (Hirochika et al. 1987). An autoradiograph of the CAT assay products after chromatography is shown. The experiment was repeated twice and reproducible results were obtained.

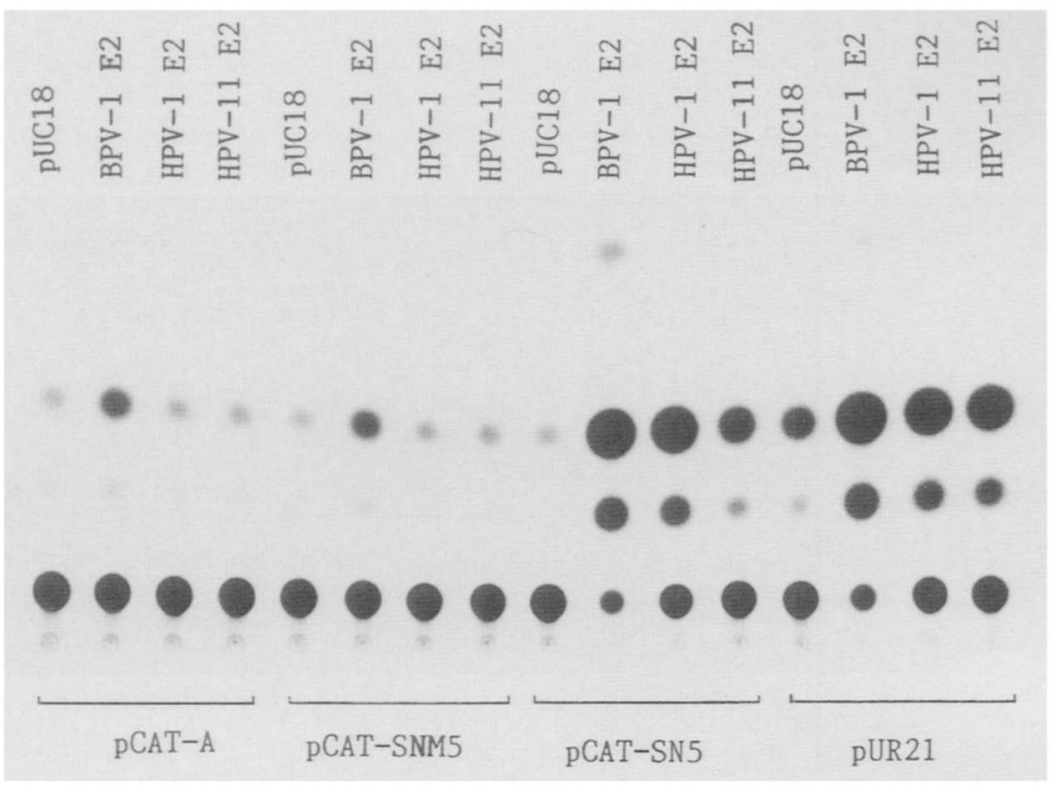

tion, total protein was analyzed by SDS-polyacrylamide gel electrophoresis (Laemmli 1970) (Fig. 5B). Only HPV-1 E2 protein was visible by Coomassie blue staining. More than $90 \%$ of the HPV-1 E2 protein was insoluble (compare lanes 5 and 6, Fig. 5B). The HPV-11 and BPV-1 E2 proteins were also enriched in the insoluble fraction (data not shown).

To test the abilities of the $\mathrm{E} 2$ proteins to interact with the HPV-11 E2-RS, filter-binding assays with crude lysates of induced bacteria and end-labeled HindIIIBamHI DNA fragments shown in Figure 6A were performed. The results are presented in Figure 6B. Fragment A carries one copy of the \#2 E2-RS and the constitutive enhancer sequence, whereas the control fragment B carries the SV40 early promoter. The induced lysates containing the E2 protein of HPV-11, HPV-1, or BPV-1 selectively trapped the A fragment on the filters. No such activity was detected in the induced control lysate prepared from bacteria carrying only the vector plasmid pRC23. These results strongly suggest that E2 proteins expressed in E. coli bind to the HPV-11 E2-RS. To substantiate the interpretation that E2-RS was responsible for the binding, we repeated the filter-binding assays using end-labeled HindIII restriction fragments containing zero to five copies of the synthetic E2-RS from the plasmids described in Figure 3 . The results are shown in Figure 7. The induced lysate containing HPV-11 E2 protein selectively retained DNA fragments carrying one or more copies of the E2-RS. However, the DNA fragment containing one copy of the E2-RS was at a competitive disadvantage to those carrying multiple copies (panels b, c, and d). Neither of the mutated motifs was retained by the same lysates (panel d, and data not shown). These results unambiguously demonstrate that HPV-11 E2 protein directly binds to the E2-RS.

The DNA binding activities of the three $\mathrm{E} 2$ proteins were characterized further following their purification
(A) PRCE2-11
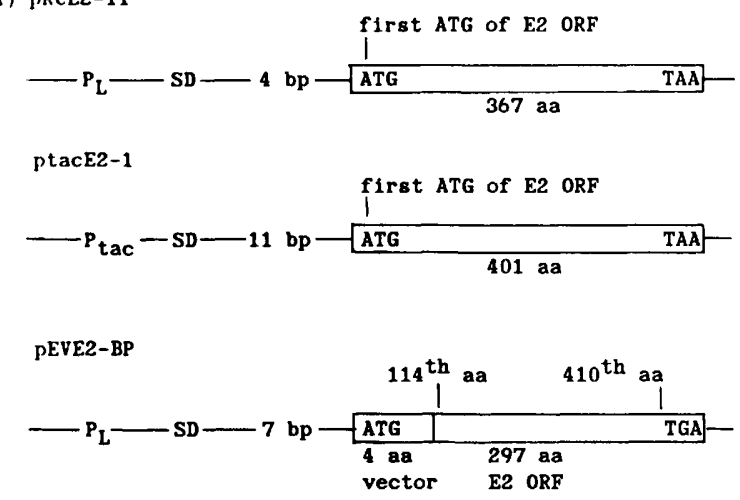

(B)

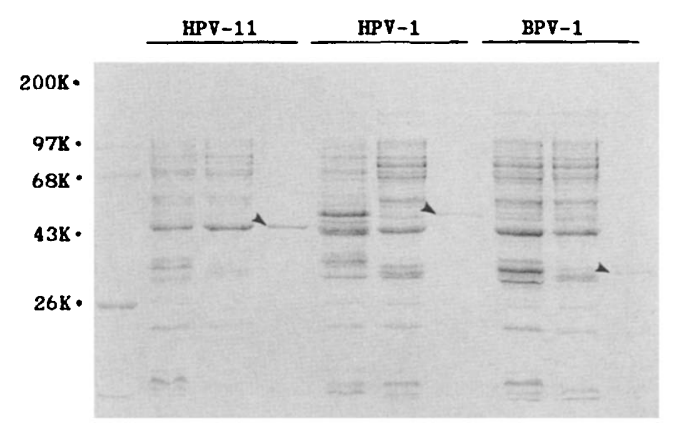

Figure 5. Expression of E2 proteins in E. coli and their purification. $(A)$ Structures of E2-expression plasmids. $(B)$ SDS-polyacrylamide gel electrophoresis of E2 proteins expressed in $E$. coli. Total proteins (lanes 2, 5, 8), soluble proteins (lanes 3, 6, 9), and E2 proteins $($ purified from the E2-responsive sequence affinity column (lanes $4,7,10$ ), were analyzed by SDS-polyacrylamide gel electrophoresis and stained with Coomassie Brilliant Blue. (Lane 1) Marker proteins (sizes shown in kilodaltons); (lanes 2-4) proteins from cells carrying pRC E2-11; (lanes 5-7) proteins from cells carrying ptac E2-1; (lanes 8-10) proteins from cells carrying pEV E2-BP. 


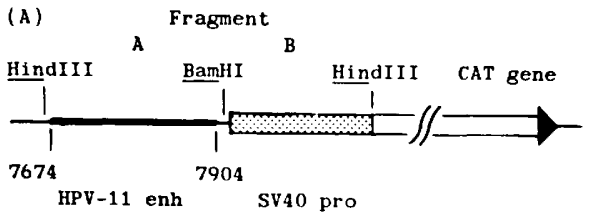

(B)

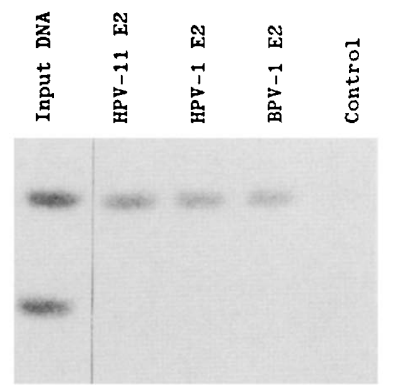

Figure 6. Filter-binding of the enhancer sequence by E2 proteins expressed in E. coli. Crude lysates prepared from induced cells carrying pRCE2-11, ptacE2-1, pEVE2-BP, or pRC23 (control) were incubated with labeled DNA as described in Materials and methods and filtered through nitrocellulose filters. $(A)$ DNA fragments used for filter-binding assay. The deletion derivative of pUR21, 24-N, was cut with HindIII and labeled at its $5^{\prime}$ ends. A and B fragments were obtained by cutting with BamHI. (B) Autoradiogram of filter-bound DNA fragments separated by electrophoresis in a $4 \%$ polyacrylamide gel.

by target sequence-specific affinity chromatography using multimerized, synthetic E2-RS as a ligand. As shown in Figure 5B (lanes 4, 7, and 10), all three E2 proteins were purified in a single passage through the column. The molecular weights were estimated to be 46, 55, and $37 \mathrm{kD}$ for the HPV-11, HPV-1, and BPV-1 E2 proteins, respectively, close to the expected molecular weights of 44,48 , and $37 \mathrm{kD}$. By using the purified E2 proteins of HPV-11, HPV-1, and BPV-1, we confirmed that the filter binding of restriction fragments containing natural or synthetic E2-RS by the crude lysates containing E2 protein was in specific response to the viral protein (data not shown). The purified HPV-11 E2 protein was then used to determine the protected sequence on both strands of the DNA in a DNase I footprinting analysis. The HPV-11 URR DNA restriction fragments used contained one or two copies of the consensus sequence $A C C \mathrm{AN}_{4} \mathrm{CGGT}$ (\#2, or \#3 and \#4) which we have shown to be the E2-RS in CAT assays. Protection of all three copies of the motif as well as of several additional, flanking nucleotides was observed (Fig. 8A). These results are summarized in Figure 8B. Identical footprinting results were obtained with purified HPV-1 and BPV-1 E2 proteins (data not shown).

\section{Discussion}

We have used sets of overlapping deletions of the HPV-11 upstream regulatory region in combination with the BPV-1 E2 protein expressed in CV-1 cells to refine the location of the HPV-11 enhancer (Fig. 1) and to map its functional elements. It is located just upstream from the transcription initiation site preceding the E6 open reading frame, analogous to that of BPV-1 (Haugen et al. 1987; Spalholz et al. 1987). Unlike that reported for BPV-1, however, we found that the HPV-11 enhancer consists of two components: an E2-independent constitutive enhancer and several copies sequence a consensus of ACCGN ${ }_{4}$ CGGT which responds to E2 proteins of HPV-1, -11, and BPV-1 (Figs. 2, 3, 4). Furthermore, either component can function as enhancer when present in multiple copies, consistent with our earlier observation that multiplication of HPV-11 enhancer-containing restriction fragments leads to higher E2-dependent and E2-independent enhancer activity (Hirochika et al. 1987). The organization of the HPV-11 URR showing the locations of the enhancer elements and other transcriptional and translational features is summarized in Figure 9.

The constitutive enhancer located just upstream of the E2-RS is required for both E2-dependent and E2-independent activities. Deletion and sequence analyses suggested that it is composed of several functional elements, some of which are homologous to the GT-, Sph-, or P-motifs present in the SV40 and polyomavirus enhancers (Zenke et al. 1986) and the recognition sequence of CTF (Table 1 and Fig. 1). The SV40 enhancer motifs are binding sites of various cellular factors (Davidson et al. 1986). CTF has been shown to stimulate RNA polymerase II transcription from promoters containing a CCAAT motif and is identical to NF-1, essential for

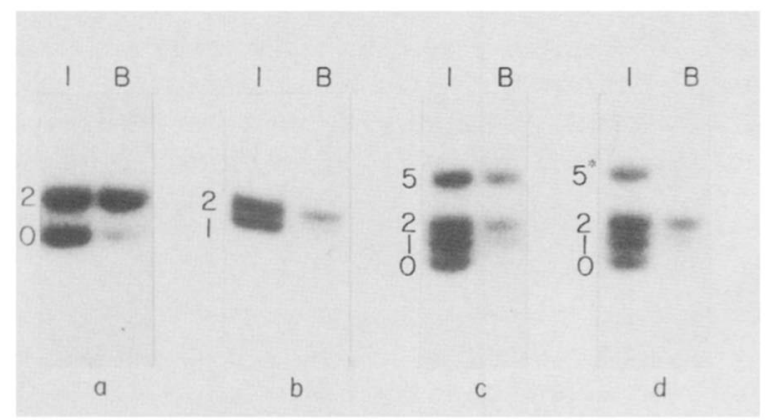

Figure 7. Filter-binding of DNA fragments carrying the cloned synthetic E2-responsive sequence or the mutated sequence mediated by the HPV-11 E2 protein. 5'-End-labeled HindIII fragments from the plasmids shown in Fig. 3 were used. The fragments contain $0,1,2$, or 5 copies of the synthetic E2-RS from pCAT-A, -SN1, -SN2, or -SN5, respectively (denoted as 0 , 1,2 , or 5 in the panels) or 5 copies of the mutant version from pCAT-SNM5 (denoted as $5^{\circ}$ in $d$ ). The labeled fragments were purified and various combinations (as noted in $a, b, c$, and $d$ ) used for the competition assay. The input DNA fragments (I) and the fragments successfully bound to, then eluted from, filters (B) were separated by electrophoresis in a $4 \%$ polyacrylamide gel and revealed by autoradiography. A crude lysate prepared from cells carrying pRC E2-11 was used as the source of E2 protein. A crude lysate of cells carrying $\mathrm{pRC} 23$, the vector for expressing the E2 protein, did not bind any fragment (data not shown, but see Fig. 6). 


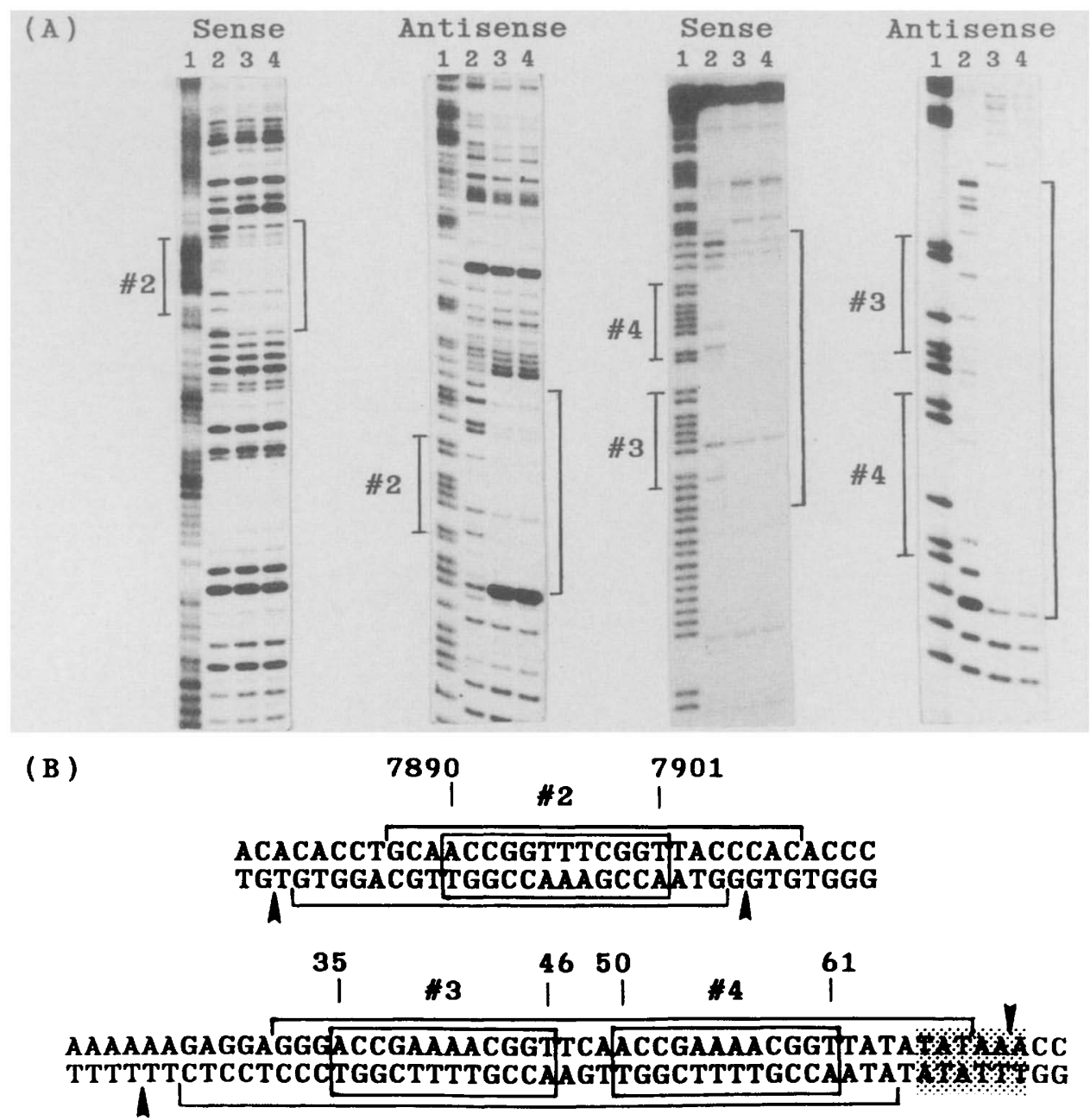

Figure 8. DNase I protection of the HPV-11 enhancer by purified HPV-11 E2 protein. $(A)$ DNase I footprints of the HPV-11 enhancer sequence. 5'-Labeled DNA fragments (20 fmoles) were incubated with different amounts of HPV-11 E2 protein purified by DNA-affinity column, then treated with DNase I, as described in Materials and methods. The DNA fragments used for the protection of the \#2 copy of the E2 motif were as follows. The RsaI-SfaNI fragment (nucleotides 7829-104), labeled at the RsaI site; and the BstNIDraI fragment (nucleotides 7719-20), labeled at the DraI site. For the protection of the \#3 and \#4 motifs, the BstEII-SfaNI fragment (nucleotides, 7899-104), labeled at the BstEII site, and the RsaI-SfaNI fragment (nucleotides 7829-104), labeled at the SfaNI site, were used. (Lane 1) Maxam-Gilbert G + A reaction; (lane 2) control DNase I digestion in the absence of the E2 protein; (lane 3) $0.2 \mu \mathrm{g}$ E2 protein; (lane $40.4 \mu \mathrm{g}$ E2 protein. The ACCGN ${ }_{4}$ CGGT motifs are indicated by bars. The sequences protected by the E2 protein are indicated by brackets. (B) Summary of DNase I footprinting analyses. The sequences protected by purified E2 proteins are shown by brackets. The ACCGN ${ }_{4}$ CGGT motifs $(\# 2, \# 3$, and \#4) are boxed. The upper strand corresponds to the sense strand. Enhanced cleavages by DNase I are indicated by arrowheads. The TATA motif of the E6 promoter is shaded.

adenoviral DNA replication (Jones et al. 1987). Multiple copies of the GT- or Sph-motifs have been shown to have enhancer activities with cell-type specificity (Ondek et al., 1987; Schirm et al. 1987). We found that multiplication of a short segment of the HPV-11 enhancer which bears homology to the GT- and Sph-motifs and the CTF recognition sequence also constitutes a potent E2-independent enhancer (Fig. 2, fragment B). It is possible that the constitutive HPV-11 enhancer helps direct the tissue-tropism of the virus. The inclusion of many such elements may serve to extend or increase the complexity of tissue-specificity of the enhancer and also to provide a means for regulation in response to epithelial differentiation. It is of particular interest that dupli- cation of sequences in the URR were found in aggressive variants of HPV-6 and HPV-11 and in HPV-33 (Boshart and zur Hausen 1986; Cole and Streeck, 1986; Rando et al. 1986; Byrne et al. 1987). Based on the results presented here, it is possible that augmented transcription in these viruses may have been partially responsible for the oncogenicity.

Several observations suggest that the constitutive enhancer that we have identified may contribute significantly to the transcriptional activity from the promoter preceding the E6 ORF. For instance, we have found that the E2-independent transcription from the HPV-11 E6 promoter in transfected cells requires only the constitutive enhancer (our unpublished results). Transcription 
from the E6 promoters of HPV-16 and -18 has been detected in cell lines derived from cervical carcinomas containing integrated HPVs (Schneider-Gadicke and Schwarz 1986; Smotkin and Wettstein 1986; Shirasawa et al. 1987; Takebe et al. 1987). These cell lines have no E2 activity (Phelps and Howley 1987) due to the integrative disruption and deletion of the trans-activator gene (Schwarz et al. 1985; Baker et al. 1987; Shirasawa et al. 1987). The E6 promoter is also active when HPV-18 DNA is transfected into some mammalian cell lines (Thierry et al. 1987).

Based on the location of the enhancers, the $\mathrm{ACCN}_{6} \mathrm{GGT}$ or the ACCGN ${ }_{4}$ CGGT motif has been suggested to be the target of E2 activation (Haugen et al. 1987; Hirochika et al. 1987; Spalholz et al. 1987). Two recent reports have shown that amino-terminal truncated or $\beta$-galactosidase fusion BPV-1 E2 proteins expressed in E. coli bind DNA fragments that contain the suspected E2-RS (Androphy et al. 1987; Moskaluk and Bastia 1987). Androphy et al. (1987) have also shown that a synthetic nucleotide containing the motif can successfully compete for this binding. However, no studies have been performed using intact E2 proteins as predicted from their ORFs nor has site-directed mutagenesis been performed to determine whether this motif is necessary and sufficient for protein binding and for transcriptional activation. We have expressed intact HPV-1 and HPV-11 proteins and amino-terminal truncated BPV-1 E2 protein (Fig. 5) and have demonstrated that all three proteins bind only to HPV-11 restriction fragments containing E2-RS and to synthetic E2-RS (Figs. 6 and 7). These proteins do not bind synthetic oligonucleotides that contain either a half-site or a mutant palindrome (Fig. 7 and data not shown). In particular, our analyses with synthetic E2-RS and mutated versions of it establish that the transcriptional activation in vivo is also sequence-specific, that a half-site or a mutated palindromic sequence is not a target for $\mathrm{E} 2$ protein activation, and that the constitutive enhancer is not required for activation when multiple copies of the E2-RS are present (Figs. 3 and 4 ).

The central six nucleotides in the $\mathrm{ACCN}_{6} \mathrm{GGT}$ motif are not conserved among all papillomaviruses, but five of them (GNTTTC) are in HPV-11 (Fig. 9). Moreover, the central four nucleotides in the anogenital tract-specific HPV are usually A or T. HPV-11 E2 protein protected a ACCGN ${ }_{5}$ GGT motif in a BPV-1 restriction fragment in pancreatic DNase I footprinting (data not shown). Accordingly, it is very likely that the sequence ACCN ${ }_{6}$ GGT would be sufficient for E2 protein binding and activation. This conclusion is supported by the cross-activation by E2 proteins of HPV-11, HPV-1, and BPV-1 on many animal and human papillomaviral enhancers (Hirochika et al. 1987). Phelps and Howley (1987) have also shown that BPV-1 E2 can activate HPV-16 enhancer. The sequence of the central six nucleotides can, however, influence the strength of association with the E2 protein, because the HPV-1 and BPV-1 E2 proteins expressed in E. coli bind to the HPV-11 E2-RS affinity column less tightly than the HPV-11 E2 protein, as evidenced by their somewhat lower purity than achieved with the HPV-11 E2 protein (Fig. 5B). A similar observation has been reported for the bacteriophage 434 operator-repressor interactions (Koudelka et al. 1987). Inspection of Figure 8 shows that the staggered DNase I footprints are centered around the E2-RS ACCN $_{6}$ GGT but not a nested ACCN ${ }_{7}$ GGT present in the \#2 motif. Comparision with footprints on copy \#3 and \#4 E2 motif indicate that the protection of nucleotides beyond the E2 motif is not sequence-specific. These results suggest that $\mathrm{ACCN}_{7} \mathrm{GGT}$ is not a target for E2 binding and that not only the sequences of the two halves of the palindrome, ACC and GGT, but also the distance between them, are stringent requirements. In summary, these experiments demonstrate unequivocally that the sequence $\mathrm{ACCN}_{6} \mathrm{GGT}$ is both necessary and sufficient for both E2 protein binding and transcriptional activation.

Proteins bound to palindromic sequences have often been shown to bind as dimers (Pabo and Sauer 1984). Our results do not bear directly on this point with respect to the E2 protein. However, a number of proteinprotein interactions can be inferred. For instance, one copy of the E2-RS has E2-dependent enhancer activity only when it is in the presence of the constitutive enhancer (Table 1 and Fig. 1). Conversely, two or more

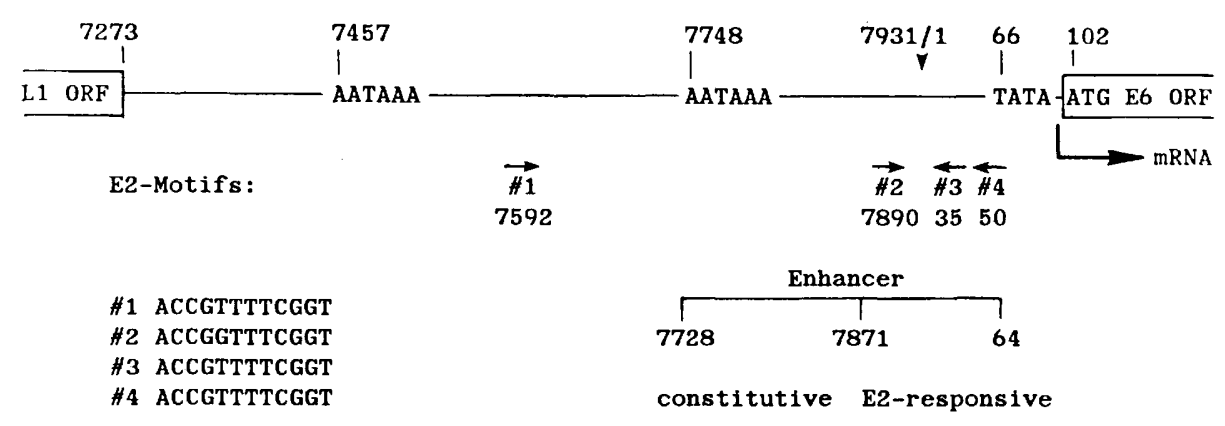

Figure 9. Transcriptional regulatory sequences in the URR of HPV-11. The URR is located between the L1 and E6 ORFs. The $3^{\prime}$ cleavage/polyadenylation signals for mRNA synthesis and the TATA motif of the E6 promoter are marked for reference. The arrows denote the locations and orientations of the 12-bp E2-motifs, the sequences of which are shown (\#1 through \#4). The two components of the enhancer, the constitutive and the E2-responsive sequences, are indicated. The boundary between the two enhancer components is near nucleotide 7889 . 
copies of the E2-RS comprise an active E2-dependent enhancer in the absence of the constitutive enhancer (Figs. 2,3 , and 4). Furthermore, if the separation between two copies of the E2-RS is modestly increased, the activity is greatly reduced, if not abolished [compare pCAT-N2 133 bp apart) with pUR27d1 (15 bp apart) in Fig. 2 and pCAT-SN2 (19 bp apart) in Fig. 3]. In vitro, DNA fragments containing one copy of the synthetic E2-RS are out-competed by those with higher copy numbers in binding to the E2 protein (Fig. 7). Thus, the E2 protein binding to its target sequence is facilitated cooperatively by additional bound E2 proteins or by other transcriptional factor(s) bound to the adjacent constitutive enhancer elements. The reason for the absence of significant effect on the enhancer activity by the deletion of the \#1 copy of the E2-motif (Table 1) might then be the relatively long distance to the constitutive enhancer and to the other E2-RS. Transcriptional factors showing these types of cooperativity have also been demonstrated in other systems (Topol et al. 1985; Learned et al. 1986). Other possible explanations for the requirements for multiple copies of the E2-RS or the E2-RS in combination with other cis elements are that protein-protein interactions may activate the $\mathrm{E} 2$ protein through conformational changes. The presence of tandem E2-responsive sequences just upstream of the putative promoter preceding the E6 ORF is conserved in the human papillomaviruses of the genital tract (Dartmann et al. 1986; Cole and Danos 1987) (see Fig. 9). The proximity to the TATA motif may be important for promoter regulation by the interaction between the E2 protein and TATA sequence binding factor (Davison et al. 1983; Parker and Topol 1984). Interestingly, the analogous tandem organization was found in the heat shock gene which is regulated by a heat shock gene-specific transcriptional factor (Topol et al. 1985). Additional evidence that E2 interactions with other transcriptional factors may play an important role in regulating gene expression is that BPV-1 E2 protein can repress certain BPV-1 promoters (A. Stenlund and M. Botchan, pers. comm.). Because papillomaviral gene expression is tied intimately to keratinocyte differentiation (Chow et al. 1987c), presumably effected by changes in the cellular transcription factors, it is reasonable to suggest that E2 interactions with these factors may modulate viral gene expression.

Of the many virus-encoded transcriptional factors that have been identified, few have been expressed in $E$. coli and shown to be biologically active (Krippl et al. 1984; Giam et al. 1986). We have expressed the HPV-11 and HPV-1 E2 proteins in E. coli by using the first ATG of the E2 ORF as an initiation codon, whereas the BPV-1 E2 protein expressed lacks its normal amino-terminal region. All three proteins can be purified to near-homogeneity by simple affinity chromatography using the synthetic E2-RS as a ligand (Fig. 5) and they retain their DNA binding specificity (Fig. 6 and our unpublished results). This demonstrates that the amino-terminal onefourth of the E2 protein is not necessary for binding to the recognition sequence. The same conclusion con- cerning the BPV-1 E2 protein has been reached by Androphy et al. (1987). In fact, the carboxy-terminal $45 \%$ of the HPV-11 E2 protein is sufficient for specific binding to the E2-RS, and it has the same footprint as the intact E2 protein (M.T. Chin, Hirochika, Hirochika, Chow, and Broker, unpubl.). The carboxy-terminal domain of E2 proteins encoded by BPV-1 (Lambert et al. 1987) and by HPV-11 (Chin et al. unpubl.) has been shown to be a distinct entity which functions as a transcriptional repressor, most likely by competition with E2 protein for binding to the E2-RS. Together these data indicate that the amino-terminus of the E2 protein is essential for the trans-activation function. It follows that the DNA binding activity is not sufficient for the transcriptional activation. E2 proteins, then, appear to contain two functional domains, a DNA binding domain and a transcriptional activation domain, as do other transcriptional factors (for a review, see Struhl 1987). This latter domain may interact with additional transcriptional factors, as already discussed. The inducible enhancer composed of multiple copies of the E2-RS is one of the simplest known. The availability of purified E2 proteins may make it possible to develop an in vitro transcriptional system subject to trans-regulation.

\section{Materials and methods}

\section{Plasmids used for CAT assays}

pCAT-A and pCAT-B (the basic enhancer assay plasmids), pUR21 carrying the HPV-11 enhancer region, and pRSE2-1, pRSE2-11, and pRSE2-BP / the eukaryotic expression plasmids of the HPV-1, HPV-11, and BPV-1 E2 ORFs, respectively/ have been described (Hirochika et al. 1987). Briefly, pCAT-A and pCAT-B contain the enhancerless SV40 early promoter and the gene encoding chloramphenicol acetyltransferase (CAT) in either orientation in the cloning vector pUC19 (see Fig. 3). The expression of the CAT gene depends on the insertion of an active enhancer sequence. pUR21 contains HPV-11 nucleotides $7072-7904$ (BamHI to BstEII) inserted at the blunt-ended SalI site in the polylinker of pCAT-A and was used to make deletion mutations. For $5^{\prime}$ deletions, pUR21 was linearized with $P_{S t} \mathrm{I}$ in the polylinker and treated with BAL31 nuclease. After cleavage at the $B a m H I$ site in the polylinker, the deleted fragments were recloned into the BamHI site and the blunt-ended Sall site of pCAT-A. For 3' deletions, pUR21 was linearized with BamHI and treated with BAL31. After digestion with PstI, the deletion fragments were cloned into the PstI site and the blunt-ended Sall site of pCAT-A. pUR26 contains nucleotides 7072-20 obtained by digestion of the HPV-11 genomic DNA clone with BamHI and Dral. pUR27 contains nucleotides 7072-64 prepared by BAL31 nuclease resection of the HPV-11 DNA from the SfaNI site (nucleotide 104). The deletion end points were determined by dideoxynucleotide sequencing (Sanger et al. 1977) of M13 clones (Messing 1983). The plasmids shown in Figure 2 were constructed by cloning the restriction fragments indicated into the polylinker sites of pCAT-A as described in the legend. The chemically synthesized complementary oligonucleotides shown in Figure 3 were cloned into the Sall site of pCAT-A or pCAT-B. Their nucleotide sequences were then confirmed by sequencing. 


\section{DNA transfection and CAT assays}

$\mathrm{CV}-1$ cells were cultured and transfected as described previously (Hirochika et al. 1987) except that $2 \mu \mathrm{g}$ of the CAT plasmid and $4 \mu \mathrm{g}$ of the E2 expression plasmid were transfected into cells on $60-\mathrm{mm}$ plates. CAT assays were performed as described (Hirochika et al. 1987), except that the cell pellet was suspended in $35 \mu \mathrm{l}$ of $0.25 \mathrm{M}$ Tris $-\mathrm{HCl}(\mathrm{pH} 7.8)$ instead of 100 $\mu 1$.

\section{Construction of E2 plasmids for expression in E. coli}

The structures of the E2-expression plasmids are shown in Figure 5A. These plasmids were constructed as follows. ptac E2-1: HPV-1 DNA was cut with SacI (nucleotide 2359), treated with BAL31 nuclease, digested with HindIII (nucleotide 3876), and cloned into the EcoRI site (blunt-ended with S1 nuclease) and the HindIII site of pKK223-3 (Pharmacia). pRC E2-11: HPV-11 DNA was cut with XmnI (nucleotide 2661), treated with BAL31 nuclease, digested with HindIII (nucleotide 4557), and cloned into the EcoRI (blunt-ended with S1 nuclease) and the HindIII sites of pRC23 (Crowl et al. 1985). The deletion end points were determined by sequencing (Maxam and Gilbert 1980). pEV E2-BP: BPV-1 DNA was cut with NarI (nucleotide 2945) and blunt-ended by filling in with E. coli DNA polymerase I (Klenow fragment). The DNA was then cut with $B a m H I$ (nucleotide 4451) and cloned into the EcoRI site (filledin with the Klenow fragment of DNA polymerase I) and the BamHI site of pEV-vrf 1 (Crowl et al. 1985).

Preparation of E. coli crude lysates and purification of E2 proteins

JM105 cells (Messing 1983) carrying ptac E2-1 were grown at $37^{\circ} \mathrm{C}$ in $\mathrm{M} 9$ medium containing $0.5 \%$ glucose, $0.5 \%$ casamino acids and ampicillin $(50 \mu \mathrm{g} / \mathrm{ml})$ to Klett 40 units and then incubated for $2 \mathrm{hr}$ with $1 \mathrm{mM}$ isopropyl $\beta$-D-thiogalactoside. RR1 (pRK248 lambda $c I_{t s}$ ) cells carrying pRC E2-11 or pEV E2-BP were grown and induced as described (Crowl et al. 1985). To prepare crude lysates for filter-binding analysis, cells from a 40-ml culture were washed, suspended in $0.25 \mathrm{ml}$ of buffer containing $50 \mathrm{~mm}$. Tris- $\mathrm{HCl}(\mathrm{pH} 7.8), 1 \mathrm{~mm}$ EDTA, $0.3 \mathrm{M} \mathrm{NaCl}$, and treated with lysozyme $(1 \mathrm{mg} / \mathrm{ml})$ at $0^{\circ} \mathrm{C}$ for $20 \mathrm{~min}$. After addition of $\mathrm{NP}-40$ to $0.2 \%$ and $\mathrm{NaCl}$ to $1 \mathrm{M}$, the lysates were centrifuged at $15,000 \mathrm{rpm}$ for $30 \mathrm{~min}$. The supernatant was used for filter-binding assays. To purify E2 proteins by sequence-specific DNA affinity chromatography, the procedures described by Kadonaga and Tjian (1986) were used. Briefly, DNA-Sepharose was prepared using multimerized complementary oligonucleotides carrying the E2-responsive sequence (SN) shown in Figure 3. Cells from $200-\mathrm{ml}$ cultures were suspended in $20 \mathrm{ml}$ of their buffer $\mathrm{Z}$ containing $0.1 \mathrm{M} \mathrm{KCl}, 2 \mathrm{mM}$ phenylmethylsulfonyl fluoride (PMSF), and $600 \mu \mathrm{g}$ of calf thymus DNA, and then sonicated. Following centrifugation at $10,000 \mathrm{rpm}$ for 10 min, the supernatant was applied to a 1-ml DNA-Sepharose column equilibrated with buffer $\mathrm{Z}$ containing $0.1 \mathrm{M} \mathrm{KCl}$. After washing with buffer $\mathrm{Z}$ containing $0.1 \mathrm{M} \mathrm{KCl}$, E2 protein was eluted with buffer $\mathrm{Z}$ containing $1 \mathrm{M} \mathrm{KCl}$ and stored at $-70^{\circ} \mathrm{C}$.

\section{Filter binding analysis}

Plasmid DNAs containing either HPV-11 DNA restriction fragments or synthetic oligonucleotides (Figs. 3 and 6 ) were digested with the restriction enzymes indicated in the legends, dephosphorylated with calf intestinal alkaline phosphatase, and then $5^{\prime}$-end-labeled with $\left(\gamma^{-32} \mathrm{P}\right)$ ATP $\left.3000 \mathrm{Ci} / \mathrm{mmole}\right)$ using T4 polynucleotide kinase. One microliter of the crude lysate of an E. coli culture expressing the E2 protein or of a control lysate was incubated at room temperature for $15 \mathrm{~min}$ with the labeled DNA (60 fmoles) in a 50- $\mu$ l reaction containing $10 \mathrm{~mm}$ Tris$\mathrm{HCl}$ (pH 7.8), $1 \mathrm{~mm}$ EDTA, $20 \mathrm{~mm} \mathrm{NaCl}$. Exogenous DNA was not necessary to eliminate nonspecific DNA binding, suggesting that the $E$. coli DNA in the lysate served as competitor. The reaction mixtures were passed through a nitrocellulose filter (Millipore HAWP, 0.45 -micron pore size) and washed with $0.5 \mathrm{ml}$ of $10 \mathrm{~mm}$ Tris- $\mathrm{HCl}(\mathrm{pH} 7.8), 50 \mathrm{~mm} \mathrm{NaCl}$. The retained DNA was eluted by incubation at $37^{\circ} \mathrm{C}$ for $2 \mathrm{hr}$ in $1 \mathrm{M}$ $\mathrm{NaCl}, 0.1 \%$ SDS, and recovered by ethanol precipitation. The DNA fragments were separated by electrophoresis in a $4 \%$ polyacrylamide gel and detected by autoradiography.

\section{DNase I footprint analysis}

Restriction fragments that were labeled with $\left(\gamma^{-32} \mathrm{P}\right)$ ATP at one 5 ' end were prepared as described in the legend to Figure 8. Different amounts of HPV-11 E2 protein purified by DNA-affinity chromatography were incubated with these DNA fragments 120 fmoles) at room temperature for $15 \mathrm{~min}$ in a $100-\mu \mathrm{l}$ reaction containing $10 \mathrm{~mm}$ Tris- $\mathrm{HCl}$ (pH 7.8), $1 \mathrm{~mm}$ EDTA, $40 \mathrm{~mm} \mathrm{KCl}$. The reaction was treated with DNase $\mathrm{I}(4 \mu \mathrm{g} / \mathrm{ml})$ for $1 \mathrm{~min}$ at room temperature after addition of $\mathrm{MgCl}_{2}$ to $10 \mathrm{mM}$ and processed as described by Galas and Schmitz (1978). Samples were electrophoresed in $10 \%$ polyacrylamide/urea gels. Marker sequence ladders were prepared by the method of Maxam and Gilbert (1980).

\section{Acknowledgments}

This project was supported by research grants for the US Public Health Service/National Institutes of Health (CA36200) and the Council for Tobacco Research-USA (\#1587). The expression plasmids pRC23 and pEV-vrf were kindly supplied by Dr. Robert Crowl. We thank Ms. Shirley Thomas for excellent assistance in the preparation of the manuscript.

\section{References}

Androphy, E.J., D.R. Lowy, and J.T. Schiller. 1987. Bovine papillomavirus E2 trans-activating gene product binds to specific sites in papillomavirus DNA. Nature 325: 70-73.

Baker, C.C. 1987. Sequence analysis of papillomavirus genomes. In The papillomaviruses (ed. N.P. Salzman and P.M. Howley). The papovaviridae, vol. 2, pp. 321-386. Plenum, New York.

Baker, C.C. and P.M. Howley. 1987. Differential promoter utilization by the bovine papillomavirus in transformed cells and productively infected wart tissues. EMBO /. 6: 10271035.

Baker, C.C., W.C. Phelps, V. Lindgren, M.J. Braun, M.A. Gonda, and P.M. Howley. 1987. Structural and transcriptional analysis of human papillomavirus type 16 sequences in cervical carcinoma cell lines. J. Virol. 61: 962-971.

Beaudenon, S., D. Kremsdorf, O. Croissant, S. Jablonska, S. Wain-Hobson, and G. Orth. 1986. A novel type of human papillomavirus associated with genital neoplasias. Nature 321: 246-249.

Boshart, M. and H. zur Hausen. 1986. Human papillomaviruses in Buschke-Lowenstein tumors: Physical state of the DNA and identification of tandem duplication in the noncoding 
region of human papillomavirus 6 subtype. I. Virol. 58: $963-966$.

Broker, T.R. and M. Botchan. 1986. Papillomaviruses: Retrospectives and prospectives. In DNA tumor viruses: Control of gene expression and replication (ed. M. Botchan, T. Grodzicker, and P.A. Sharp). Cancer Cells 4: 17-36.

Broker, T.R. and L.T. Chow. 1986. Human papilloma viruses of the genital mucosa: Electron microscopic analyses of DNA heteroduplexes formed with HPV types 6, 11 and 18. In DNA tumor viruses: Control of gene expression and replication (ed. M. Botchan, T. Grodzicker, and P.A. Sharp). Cancer Cells 4: 589-594.

Broker, T.R. 1987. Structure and genetic expression of papillomaviruses. Obstet. Gynecol. Clinics North America 14: 329-348.

Byrne, J.C., M-S Tsao, R.S. Fraser, and P.M. Howley. 1987. Human papillomavirus-11 DNA in a patient with chronic laryngotracheobronchial papillomatosis and metastatic squamous-cell carcinoma of the lung. New Engl. I. Med. 317: 873-878.

Chow, L.T., M. Nasseri, S.M. Wolinsky, and T.R. Broker. 1987a. Human papillomavirus types 6 and 11 mRNAs from genital condylomata. J. Virol. 61: 2581-2588.

Chow, L.T., S.S. Reilly, T.R. Broker, and L.B. Taichman. 1987b. Identification and mapping of human papillomavirus type 1 RNA transcripts recovered from plantar warts and infected epithelial cell cultures. J. Virol. 61: 1913-1918.

Chow, L.T., H. Hirochika, M. Nasseri, M.H. Stoler, S.M. Wolinsky, M.T. Chin, R. Hirochika, D.S. Arvan, and T.R. Broker. 1987c. Human papillomavirus gene expression. In Papillomaviruses (ed. I.L. Brandsma, B.M. Steinberg, and L.B. Taichman). Cancer Cells 5: 55-72.

Cole, S.T. and O. Danos. 1987. Nucleotide sequence and comparative analysis of the human papillomavirus type 18 genome. Phylogeny of papillomaviruses and repeated structure of the E6 and E7 gene products. J. Mol. Biol. 193: 599608.

Cole, S.T. and R.E. Streeck. 1986. Genome organization and nucleotide sequence of human papillomavirus type 33, which is associated with cervical cancer. $J$. Virol. 58: 991995.

Croissant, O., V. Testaniere, and G. Orth. 1982. Mise en evidence et localisation de regions conservees dans les genomes du papillomavirus humain la et du papillomavirus bovin 1 par analyse $\mathrm{d}$ " "heteroduplex" au microscope electronique. Compte Rendu Acad. Sci. (Paris) 294: 581-586.

Crowl, R., C. Seamans, P. Lomedico, and S. McAndrew. 1985. Versatile expression vectors for high-level synthesis of cloned gene products in Escherichia coli. Gene 38: 31-38.

Danos, O., E. Georges, G. Orth, and M. Yaniv. 1985. Fine structure of the cottontail rabbit papillomavirus mRNAs expressed in the transplantable $\mathrm{Vx} 2$ carcinoma. I. Virol. 53: 735-741.

Dartmann, K., E. Schwarz, L. Gissmann, and H. zur Hausen. 1986. The nucleotide sequence and genome organization of human papilloma virus type 11. Virology 151: 124-130.

Davidson, I., C. Fromental, P. Augereau, A. Wildeman, M. Zenke, and P. Chambon. 1986. Cell-type specific protein binding to the enhancer of simian virus 40 in nuclear extracts. Nature 323: $544-548$.

Davison, B.L., J-M. Egly, E.R. Mulvihill, and P. Chambon. 1983. Formation of stable preinitiation complexes between eukaryotic class B transcription factors and promoter sequences. Nature 301: 680-686.

Galas, D.J. and A. Schmitz. 1978. DNAase footprinting: A simple method for the detection of protein-DNA binding specificity. Nucleic Acids Res. 5: 3157-3170.

Giam, C.-Z., M. Nerenberg, G. Khoury, and G. Jay. 1986. Expression of the complete human $\mathrm{T}$-cell leukemia virus type I pX coding sequence as a functional protein in Escherichia coli. Proc. Natl. Acad. Sci. 83: 7192-7196.

Giri, I., O. Danos, and M. Yaniv. 1985. Genomic structure of the cottontail rabbit (Shope) papillomavirus. Proc. Natl. Acad. Sci. 82: 1580-1584.

Haugen, T.H., T.P. Cripe, G.D. Ginder, M. Karin, and L.P. Turek. 1987. Trans-activation of an upstream early gene promoter of bovine papilloma virus-1 by a product of the viral E2 gene. EMBO /. 6: 145-152.

Hirochika, H., T.R. Broker, and L.T. Chow. 1987. Enhancers and trans-acting E2 transcriptional factors of papillomaviruses. I. Virol. 61: 2599-2606.

Jones, K.A., J.T. Kadonaga, P.J. Rosenfeld, T.J. Kelly, and R. Tjian. 1987. A cellular DNA-binding protein that activates eukaryotic transcription and DNA replication. Cell 48: 79 89.

Kadonaga, J.T. and R. Tiian. 1986. Affinity purification of sequence-specific DNA binding proteins. Proc. Natl. Acad. Sci 83: $5889-5893$.

Koudelka, G.B, S.C. Harrison, and M. Ptashne. 1987. Effect of non-contacted bases on the affinity of 434 operator for 434 repressor and Cro. Nature 326: 886-888.

Kreider, J.W., M.K. Howett, S.A. Wolfe, G.L. Bartlett, R.J. Zaino, T.V. Sedlacek, and R. Mortel. 1985. Morphological transformation in vivo of human uterine cervix with papillomavirus from condylomata acuminata. Nature 317: $639-641$.

Krippl, B., B. Ferguson, M. Rosenberg, and H. Westphal. 1984. Functions of purified E1A protein microinjected into mammalian cells. Proc. Natl. Acad. Sci. 81: 6988-6992.

Kristie, T.M. and B. Roizman. 1986. DNA-binding site of major regulatory protein alpha4 specifically associated with promoter-regulatory domains of alpha genes of herpes simplex virus type 1. Proc. Natl. Acad. Sci. 83: 4700-4704.

Krubke, J., J. Kraus, H. Delius, L.T. Chow, T.R. Broker, T. Iftner, and $H$. Pfister. 1987. Genetic relationship among human papillomaviruses associated with benign and malignant tumours of patients with epidermodysplasia verruciformis. J. Gen. Virol. 68: 3091-3103.

Laemmli, U.K. 1970. Cleavage of structural proteins during the assembly of the head of bacterial phage T4. Nature 227: 680-685.

Lambert, P.F., B.A. Spalholz, and P.M. Howley. 1987. A transcriptional repressor encoded by BPV-1 shares a common carboxy-terminal domain with the E2 transactivator. Cell 50: $69-78$.

Learned, R. M., T.K. Learned, M.M. Haltiner, and R.T. Tjian. 1986. Human rRNA transcription is modulated by the coordinate binding of two factors to an upstream control element. Cell 45: 847-857.

Maxam, A.M. and W. Gilbert. 1980. Sequencing end-labelled DNA with base-specific chemical cleavages. Methods Enzymol. 65 (part 1): 499-560.

McKnight S. and R. Tjian. 1986. Transcriptional selectivity of viral genes in mammalian cells. Cell 46: 795-805.

Messing, J. 1983. New M13 vectors for cloning. Methods Enzymol. 101: 20-78.

Moskaluk, C. and D. Bastia. 1987. The E2 'gene' of bovine papillomavirus encodes an enhancer binding protein. Proc. Natl. Acad. Sci. 84: 1215-1218.

Nasseri, M. and F. Wettstein. 1984. Differences exist between 
viral transcripts in cottontail rabbit papillomavirus-induced benign and malignant tumors as well as non-virus-producing and virus-producing tumors. I. Virol. 51: 706-712.

Nasseri, M., R. Hirochika, T.R. Broker, and L.T. Chow. 1987. A human papilloma virus type 11 transcript encoding an E1E4 protein. Virology 159: 433-439.

Ondek B., A. Shepard, and W. Herr. 1987. Discrete elements within the SV40 enhancer region display different cell-specific enhancer activities. EMBO I. 6: 1017-1025.

Pabo, C.O. and R.T. Sauer. 1984. Protein-DNA recognition. Annu. Rev. Biochem. 53: 293-321.

Parker, C.S. and J. Topol. 1984. Drosophila RNA polymerase II transcription factor contains a promoter-region-specific DNA-binding activity. Cell 36: 357-369.

Pater, M.M. and A. Pater. 1985. Human papillomavirus types 16 and 18 sequences in carcinoma cell lines of the cervix. Virology 145: 313-318.

Phelps, W.C. and P.M. Howley. 1987. Transcriptional transactivation by the human papillomavirus type 16 E2 gene product. I. Virol. 61: 1630-1638.

Phelps, W.C., S.L. Leary, and A.J. Faras. 1985. Shope papillomavirus transcription in benign and malignant rabbit tumors. Virology 146: 120-129.

Rando, R.F., W.D. Lancaster, P. Han, and C. Lopez. 1986. The noncoding region of HPV-6VC contains two distinct transcriptional enhancing elements. Virology 155: 545-556.

Sanger, F., S. Nicklen, and A.R. Coulson. 1977. DNA sequencing with chain-terminating inhibitors. Proc. Natl. Acad. Sci. 74: 5463-5467.

Schirm, S., J. Jiricny and W. Schaffner. 1987. The SV4O enhancer can be dissected into multiple segments, each with a different cell type specificity. Genes Dev. 1: 65-74.

Schneider-Gadicke, A. and E. Schwarz. 1986. Different human cervical carcinoma cell lines show similar transcription patterns of human papillomavirus type 18 early genes. EMBO $/$. 5: 2285-2292.

Schwarz, E., U.K. Freese, L. Gissmann, W. Mayer, B. Roggenbuck, A. Stremlau, and H. zur Hausen. 1985. Structure and transcription of human papillomavirus sequences in cervical carcinoma cells. Nature 314: 111-114.

Shirasawa, H., Y. Tomita, S. Sekiya, H. Takamizawa, and B. Simizu. 1987. Integration and transcription of human papillomavirus type 16 and 18 sequences in cell lines derived from cervical carcinomas. I. Gen. Virol. 68: 583-591.

Smotkin, D. and F.O. Wettstein. 1986. Transcription of human papillomavirus type 16 early genes in a cervical cancer and a cancer-derived cell line and identification of the $\mathrm{E} 7$ protein. Proc. Natl. Acad. Sci. 83: 4680-4684.

Spalholz, B.A., Y.-C. Yang, and P.M. Howley. 1985. Transactivation of a bovine papilloma virus transcriptional regulatory element by the E2 gene product. Cell 42: 183-191.

Spalholz, B.A., P.F. Lambert, C.L. Yee, and P.M. Howley. 1987. Bovine papillomavirus transcriptional regulation: Localization of the E2-responsive elements of the long control region. J. Virol. 61: 2128-2137.

Stenlund, A., J. Zabielski, H. Ahola, J. Moreno-Lopez, and U. Pettersson. 1985. Messenger RNAs from the transforming region of bovine papilloma virus type 1. I. Mol. Biol. 182: $541-554$.

Struhl, K. 1987. Promoter activator proteins and the mechanism of transcription initiation in yeast. Cell 49: 295-297.

Takebe, N., Y. Tsunokawa, S. Nozawa, M. Terada, and T. Sugimura. 1987. Conservation of E6 and E7 regions of human papillomavirus types 16 and 18 present in cervical cancers. Biochem. Biophs. Res. Commun. 143: 837-844.
Thierry, F., J.M. Heard, and M. Yaniv. 1987. Characterization of a transcriptional promoter of human papillomavirus 18 and modulation of its expression by simian virus 40 and adenovirus early antigens. J. Virol. 61: 134-142.

Topol J., D.M. Ruden, and C.S. Parker. 1985. Sequences required for in vitro transcriptional activation of a Drosophila hsp 70 gene. Cell 42: 527-537.

Weiher H., M. Konig, and P. Gruss. 1983. Multiple point mutations affecting the simian virus 40 enhancer. Science 219: 626-631.

Wong-Staal, F. and R.C. Gallo. 1985. Human T-lymphotropic retroviruses. Nature 317: 395-403.

Yang, Y.-C., H. Okayama, and P.M. Howley. 1985. Bovine papillomavirus contains multiple transforming genes. Proc. Natl. Acad. Sci. 82: 1030-1034.

Yasumoto, S., J. Doniger, and J.A. DiPaolo. 1987. Differential early viral gene expression in two stages of human papillomavirus type 16 DNA-induced malignant transformation. Mol. Cell. Biol. 7: 2165-2172.

Yee, C. I. Krishnan-Hewlett, C.C. Baker, R. Schlegel, and P.M. Howley. 1985. Presence and expression of human papillomavirus sequences in human cervical carcinoma cell lines. Am. I. Pathol. 119: 361-366.

Yoshinaga, S.K., N. Dean, M. Han, and A.J. Berk. 1986. Adenovirus ElA functions stimulate transcription by RNA polymerase-III. Evidence for an ElA-dependent increase in transcription factor-IIIC concentration. EMBO I. 5: 343-354.

Zenke, M., T. Grundstrom, H. Matthes, M. Wintzerith, C. Schatz, A. Wildeman, and P. Chambon. 1986. Multiple sequence motifs are involved in SV40 enhancer function. EMBO \%. 5: 387-397.

zur Hausen, H. and A. Schneider. 1987. The role of papillomaviruses in human anogenital cancer. In The papillomaviruses (ed. N.P. Salzman and P.M. Howley), The Papovaviridae, vol. 2; pp, 245-264. Plenum, New York. 


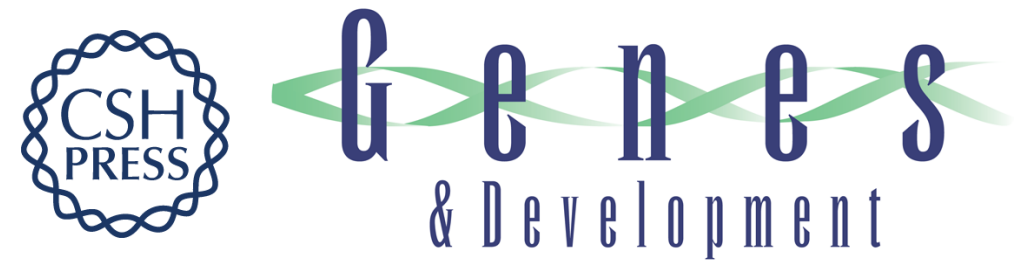

\section{Functional mapping of the human papillomavirus type 11 transcriptional enhancer and its interaction with the trans-acting E2 proteins.}

H Hirochika, R Hirochika, T R Broker, et al.

Genes Dev. 1988, 2:

Access the most recent version at doi:10.1101/gad.2.1.54

References This article cites 68 articles, 23 of which can be accessed free at:

http://genesdev.cshlp.org/content/2/1/54.full.html\#ref-list-1

License

Email Alerting Receive free email alerts when new articles cite this article - sign up in the box at the top

Service right corner of the article or click here.

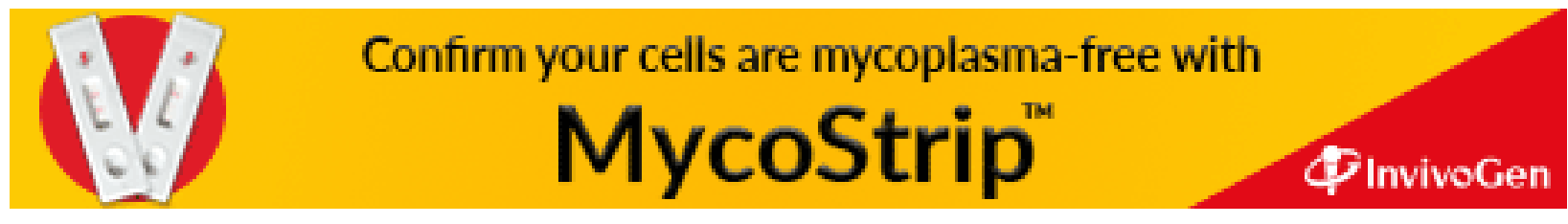

